Tema: Solidificação / Lingotamento

\title{
INFLUÊNCIA DA REFRIGERAÇÃO SECUNDÁRIA NO APARECIMENTO DE TRINCAS SUB-SUPERFICIAIS NOS TARUGOS PRODUZIDOS NA VSBM*
}

\author{
Fernando Vital Silva ${ }^{1}$ \\ Ely da Silva Araújo Junior ${ }^{2}$ \\ Jonathan Nicholas da Silva Navarro \\ Maíra Lois Rodrigues de Oliveira ${ }^{4}$ \\ Paulo Sérgio de Souza ${ }^{5}$
}

\section{Resumo}

O processo de lingotamento contínuo consiste de uma série de etapas que promoverão a extração de calor de maneira controlada do aço líquido, com o objetivo de promover sua solidificação. Uma vez que a solidificação é considerada uma transformação de fase, regida essencialmente pela troca térmica, o enfoque do processo de lingotamento contínuo se encontra direcionado para o perfil térmico de resfriamento do aço desenvolvido ao longo dos veios da máquina. É extremamente importante para a qualidade final do tarugo que este processo de extração de calor ocorra a taxas controladas, de maneira contínua e uniforme em todas suas faces. Segregação, trincas e romboidade são alguns dos problemas de qualidade que podem ser originados devido a um controle não assertivo ou deficiência do sistema de refrigeração. Os tarugos lingotados do aço 1545-D, produzidos na máquina de lingotamento contínuo da Votorantim Siderurgia Barra Mansa, apresentavam com frequência trincas sub-superficiais nas quatro direções de resfriamento e a uma distância constante da superfície do tarugo. Através de equações de solidificação foi constatado que a profundidade em que as trincas se encontravam nos tarugos correspondia a um trecho da máquina no qual existia gap de refrigeração, provocando reaquecimento do material e o surgimento de trincas devido ao regime de contração/dilatação ao qual o mesmo estava submetido. Tais conclusões permitiram comprovar falha no projeto de refrigeração secundária da máquina.

Palavras-chave: Lingotamento contínuo; Refrigeração secundária; Trincas sub-superficiais.

\section{INFLUENCE OF SECONDARY COOLING IN THE APPEARANCE OF SUB SURFACE CRACKS ON BILLETS PRODUCED AT VOTORANTIM STEEL BARRA MANSA}

\begin{abstract}
Continuous casting consists of a series of steps that will promote the extraction of heat of the liquid steel in a controlled manner, aiming to promote its solidification. Since solidification is considered a phase transformation governed mainly by thermal exchange, the focus of continuous casting is to understand the cooling thermal profile of the steel developed over the strands of the machine. It is extremely important to the final quality of the billet that the heat extraction occurs at controlled rates, and happens in a continuous and uniform way in all of its faces. Segregation, cracks and rhomboidity are some of the quality problems that can be generated due to a non-assertive control or deficiency of the cooling system. The billets of 1545- D steel produced in the continuous casting machine at Votorantim Steel in Barra Mansa, Brazil, were frequently produced with sub-superficial cracks in all four directions of cooling and at a constant distance of the billet's surface. Through solidification equations, it was found that the depth at which the cracks were being generated at the billets corresponded exactly with a portion of the machine in which there was a cooling gap, causing reheating of the material at that point and the appearance of cracks due to contraction/dilation regime to which it was submitted. These findings allowed to prove flaw in the design of the cooling system of the machine.

Keywords: Continuous casting; Secondary cooling; Halfwaycracks.

1 Graduando em Eng. de Controle e Automação, Técnico especialista em aciaria, Votorantim Siderurgia, Volta Redonda, RJ, Brasil.

2 Engenheiro Metalurgista, M.Sc., Coordenador de produção de aciaria, Votorantim Siderurgia, Ouro Preto, MG, Brasil.

3 Engenheiro Metalurgista, Gerente de aciaria, Votorantim Siderurgia, Volta Redonda, RJ, Brasil.

4 Engenheira Metalurgista, Engenheira Processos, Votorantim Siderurgia, Ouro Preto, MG, Brasil.

5 Técnico Metalúrgico, Técnico Especialista em aciaria, Votorantim Siderurgia, Barra Mansa, RJ, Brasil.
\end{abstract}

\footnotetext{
* Contribuição técnica ao $45^{\circ}$ Seminário de Aciaria - Internacional, 25 a 28 de maio de 2014, Porto Alegre, RS, Brasil.
} 


\section{INTRODUÇÃO}

O processo de lingotamento contínuo consiste de uma série de etapas que têm por finalidade promover a extração de calor do aço líquido de maneira controlada, obtendo-se como produto o aço solidificado nas mais diversas formas e dimensões. A completa solidificação do metal líquido se dá através de três zonas de refrigeração características da máquina de lingotamento contínuo, a saber: zona de refrigeração primária, zona de refrigeração secundária e zona de radiação livre, Figura 1. Segue uma breve descrição destas zonas de refrigeração:

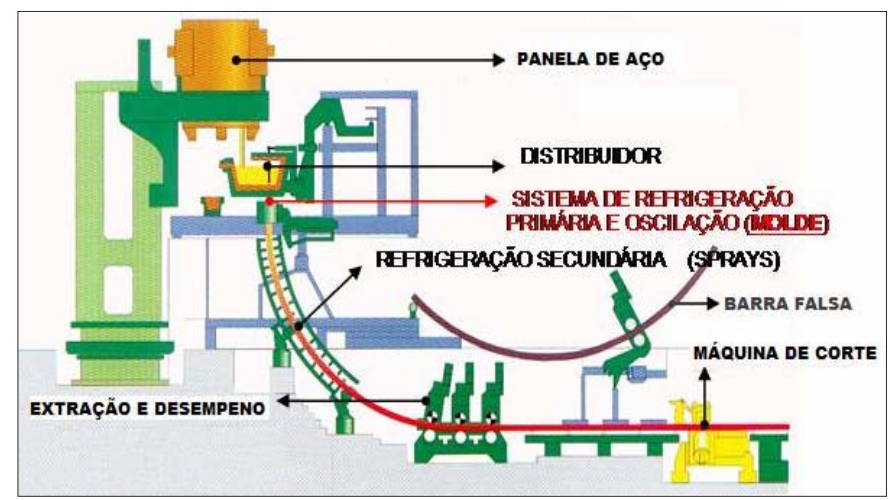

Figura 1. Layout máquina de lingotamento contínuo [1].

- Refrigeração primária: ocorre em um equipamento denominado molde, que tem como função primordial, através do resfriamento primário, propiciar a formação de uma "pele" sólida de aço de tal maneira que ao sair do molde, esta pele solidificada seja suficientemente espessa para resistir à pressão ferrostática do aço líquido em seu núcleo;

- Refrigeração secundária: é promovida através de um conjunto de equipamentos compreendidos entre a saída do molde até o final do conjunto de sprays. O resfriamento é realizado pela aspersão de água através de bicos de spray posicionados de modo a distribuir uniformemente a água pelas quatro faces do tarugo.

- Refrigeração natural (zona de radiação livre): é a etapa que completa o processo de solidificação do tarugo. A extração de calor ocorre através da radiação do metal para o ambiente [2].

Uma vez que a solidificação é considerada um processo de transformação de fase, sendo regida essencialmente pela extração de calor do metal promovida através das zonas de refrigeração, o enfoque do processo de lingotamento contínuo se encontra direcionado para o perfil térmico de resfriamento do aço desenvolvido ao longo dos veios da máquina. Tal perfil térmico dependerá de uma série de parâmetros de processo característicos para um determinado tipo de aço, como também, de detalhes do projeto da máquina de lingotamento contínuo.

São inúmeras as variáveis de processo que têm influência sob a configuração do perfil térmico desenvolvido durante o lingotamento contínuo dos aços. Superheat, pressão e qualidade da água de refrigeração do molde, velocidade de lingotamento, vazão e qualidade da água dos sprays são apenas alguns destes parâmetros. Já no que diz respeito ao projeto da máquina de lingotamento, podem-se citar como fatores que impactam no perfil térmico: quantidade e tipo de bico de spray por zona, distância entre os bicos de spray, comprimento das zonas de sprays, dentre outros.

* Contribuição técnica ao $45^{\circ}$ Seminário de Aciaria - Internacional, 25 a 28 de maio de 2014, 
As características da microestrutura bruta de fusão do tarugo são também fortemente influenciadas pelo perfil térmico de resfriamento executado durante 0 processo de lingotamento. Assim, torna-se extremamente importante para a qualidade final do tarugo, que este processo de extração de calor ocorra a taxas controladas, de maneira contínua e uniforme em todas suas faces. Fenômenos como a dilatação e contração do tarugo durante os períodos de resfriamento e reaquecimento ou alterações súbitas de gradientes térmicos na "casca" sólida, já formada, são os principais fatores responsáveis da geração de defeitos no produto final. Dentre os problemas de qualidade que podem ser originados devido a um controle não assertivo ou deficiência do sistema de refrigeração, estão: segregação, trincas e romboidade.

No presente artigo, trataremos particularmente do defeito tipo trinca subsuperficial halfway cracks. Trata-se de uma descontinuidade interna, que se localiza de modo que parece delinear a "pele" do tarugo [3]. A origem principal do surgimento deste tipo de defeito se encontra no resfriamento secundário. Mudanças bruscas na intensidade de extração de calor entre as distintas zonas de spray permitem um reaquecimento da camada de metal já solidificada, submetendo-o a tensões térmicas. Desta forma, a camada sólida trinca na interface sólido/líquido. Vale ressaltar que valores de reaquecimento da superfície do tarugo da ordem ou superiores de $100^{\circ} \mathrm{C}$ e $50^{\circ} \mathrm{C}$, para alguns casos, já são considerados elevados e contribuem para a ocorrência do defeito. As variações de extração de calor, por sua vez, podem estar associadas a uma configuração inadequada das zonas de spray ou vazão reduzida de água na refrigeração secundária [4].

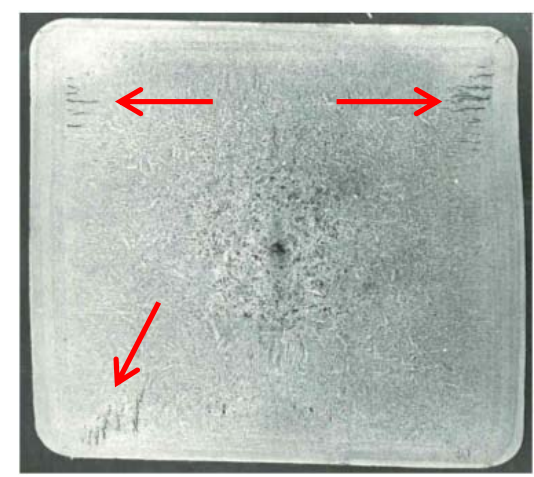

Figura 2. Macrografia da seção tranversal de tarugo mostrando trincas subsuperciais [5].

Os tarugos lingotados do aço 1545-D, produzidos na máquina de lingotamento contínuo da aciaria da VSBM, após início de operação do novo sistema de refrigeração secundária passaram a apresentar com frequência trincas subsuperficiais nas quatro direções de resfriamento e a uma distância constante da superfície do tarugo. O sistema de refrigeração secundária anterior, composto por bicos de spray de jato tipo cone cheio (full cone nozzle), foi substituído por um sistema de bicos de jato retangular cone cheio de intensidade de refrigeração três vezes maior. Através de análises macrográficas da seção transversal dos tarugos, associadas a equações de solidificação foi possível identificar a causa fundamental do defeito, apontando para uma falha no projeto de refrigeração secundária da máquina.

* Contribuição técnica ao 450 Seminário de Aciaria - Internacional, 25 a 28 de maio de 2014, 


\section{MATERIAL E MÉTODOS}

Após o início e estabilização das operações do novo sistema de refrigeração secundária da máquina de lingotamento contínuo da Votorantim Siderurgia Barra Mansa, foram acompanhadas na aciaria todas as etapas do processo de produção de uma corrida do aço 1545-D, conforme Tabela 1.

Tabela 1. Detalhe da corrida analisada

\begin{tabular}{|c|c|c|c|c|c|}
\hline \multirow{2}{*}{ Número da corrida } & \multicolumn{5}{|c|}{ Composição química (\%) } \\
\cline { 2 - 6 } & $\mathrm{C}$ & $\mathrm{Mn}$ & $\mathrm{Si}$ & $\mathrm{P}$ & $\mathrm{S}$ \\
\hline 1000023844 & 0,480 & 1,150 & 0,300 & 0,031 & 0,033 \\
\hline
\end{tabular}

Foram escolhidas para análise corridas do aço 1545-D devido a seus altos teores em composição química de carbono e manganês. Elevados teores de carbono e manganês tornam este tipo de aço mais susceptível ao fenômeno de micro segregação e por consequência mais sensível ao aparecimento de trincas térmicas nas zonas interdendríticas fragilizadas pela segregação.

Após lingotamento, foi devidamente identificada e retirada uma amostra de seção transversal do tarugo por veio em operação da corrida a ser analidasa, através de corte com maçarico a uma distância mínima de $200 \mathrm{~mm}$ da face dos tarugos. Em seguida, as amostras foram cortadas em serra com espessura de aproximadamente $20 \mathrm{~mm}$ e encaminhadas para o laboratório para preparação das mesmas para análise macrográfica.

No laboratório, apenas uma das faces de cada amostra foi lixada por meio de máquina lixadeira até que os riscos da face das amostras originados do corte de serra fossem removidos. Em seguida, as amostras foram completamente imersas, com a face a ser decapada voltada para cima, durante 30 minutos, ou até se obter a revelação necessária das macroestruturas, em solução de ácido clorídrico. A solução ácida foi anteriormente à decapagem, aquecida durante 40 minutos. Depois de completado o tempo de ataque químico das amostras, as mesmas foram retiradas do banho de ácido e neutralizadas em banho de cal, por aproximadamente 30 min. As amostras, então, foram lavadas em água corrente, secas e submetidas à análise macrográfica pelo técnico do laboratório.

\section{RESULTADOS E DISCUSSÃO}

A fim de se analisar as características macroestruturais dos tarugos lingotados segundo novo sistema de refrigeração secundária da máquina de lingotamento contínuo, em especial o surgimento de trincas subsuperficias, foram retiradas amostras da seção transversal dos tarugos de cada veio para análise macrográfica. As cinco amostras foram identificadas conforme a Tabela 2.

Tabela 2. Identificação das amostras por veio

\begin{tabular}{|c|c|c|c|c|c|c|c|}
\hline AÇO & SEÇÃO & CORRIDA & VEIO 1 & VEIO 2 & VEIO 3 & VEIO 4 & VEIO 5 \\
\hline 1545-D & $130 \mathrm{~mm}$ & 1000023844 & amostra 1 & amostra 2 & amostra 3 & amostra 4 & amostra 7 \\
\hline
\end{tabular}

A curva de intensidade de refrigeração secundária do lingotamento contínuo mostra a vazão de água de refrigeração em litros por minuto disponíveis para cada metro quadrado de metal. A Figura 3 representa a curva de intensidade de refrigeração,

* Contribuição técnica ao $45^{\circ}$ Seminário de Aciaria - Internacional, 25 a 28 de maio de 2014, 
após início de operação do novo sistema de refrigeração secundária, para a corrida analisada. A intensidade de refrigeração secundária é mostrada por zona e tendo como referência a distância desde o menisco do molde em milímetros.

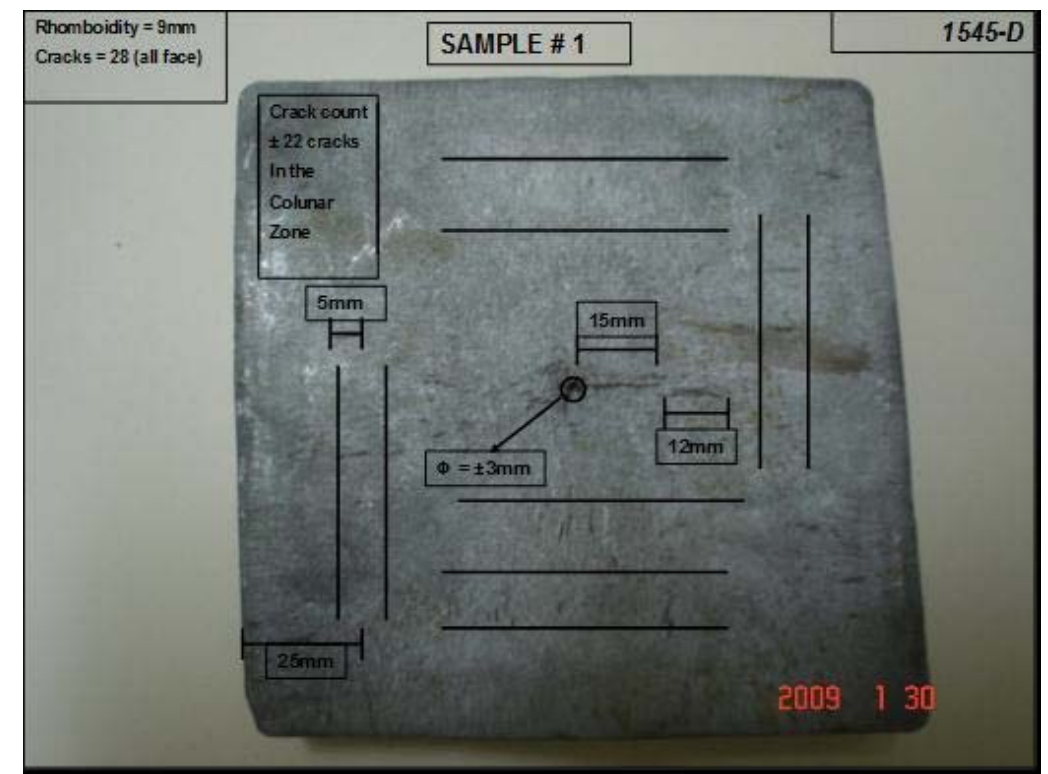

Figura 3. Curva de intensidade de refrigeração secundária [6].

Pode-se notar entre a zona 2 (Z2) e a zona 3a (Z3a) a existência de um gap no sistema de refrigeração secundária, ou seja, região considerável na qual o metal sendo lingotado percorre sem incidência direta de água de refrigeração. Este fato pode levar a camada externa do metal já solidificada a sofrer um reaquecimento, uma vez que em seu interior existe ainda poço de metal líquido.

As figuras 4 a 8 mostram os resultados obtidos a partir das análises macrográficas das amostras de seção transversal dos tarugos, retiradas por veio em operação no lingotamento contínuo.

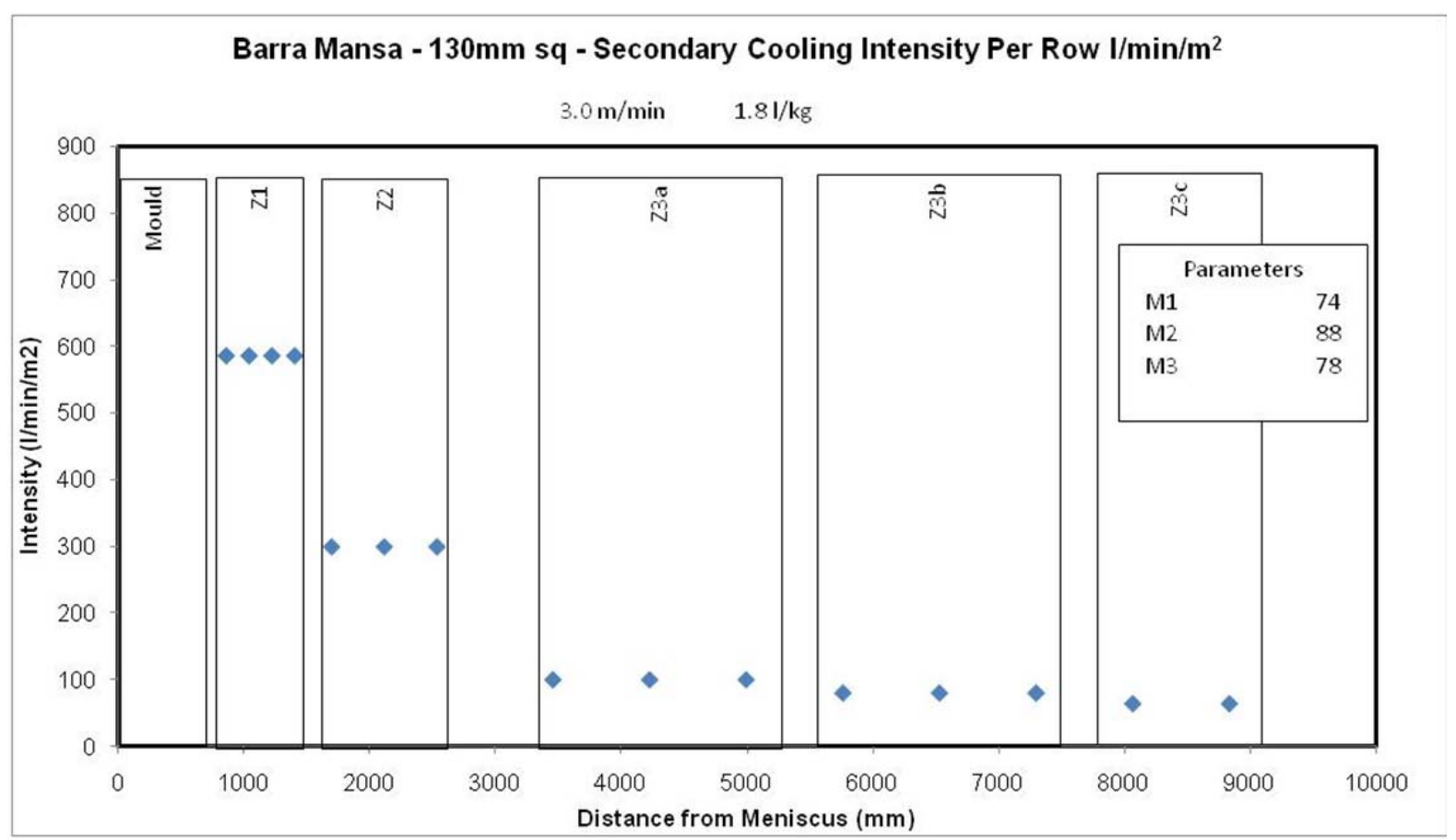

Figura 4. Macrografia amostra 1.

* Contribuição técnica ao 450 Seminário de Aciaria - Internacional, 25 a 28 de maio de 2014, Porto Alegre, RS, Brasil. 


\section{ACIARAA STEELMAKING}

45 $5^{\circ}$ SEMINÁRIO DE ACIARIA - INTERNACIONAL

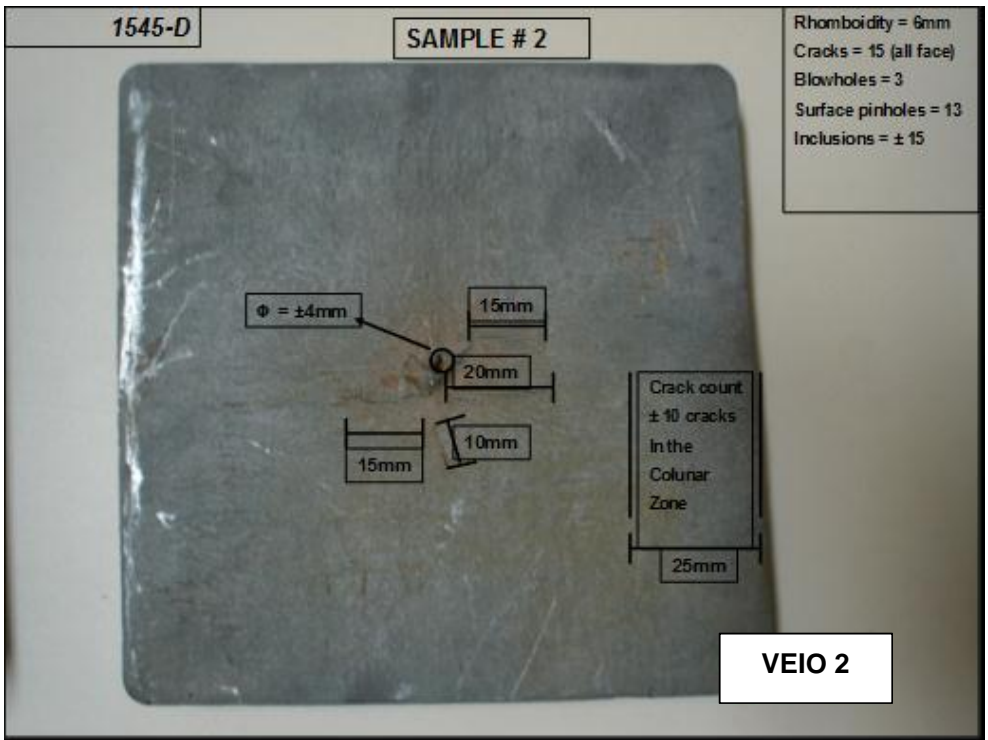

Figura 5. Macrografia amostra 2.

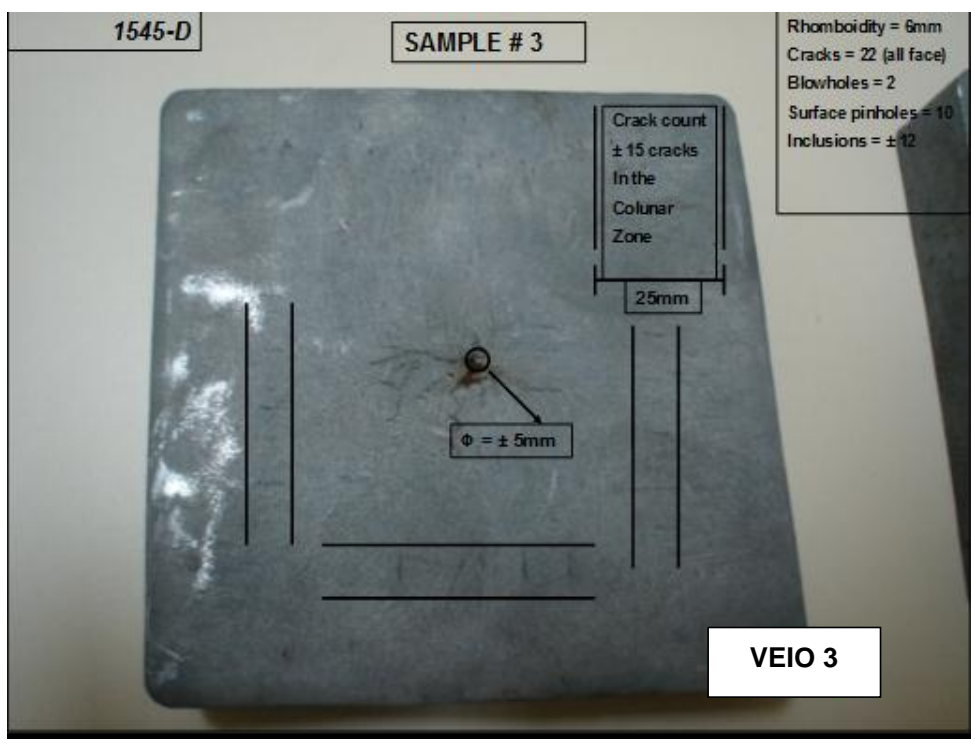

Figura 6. Macrografia amostra 3.

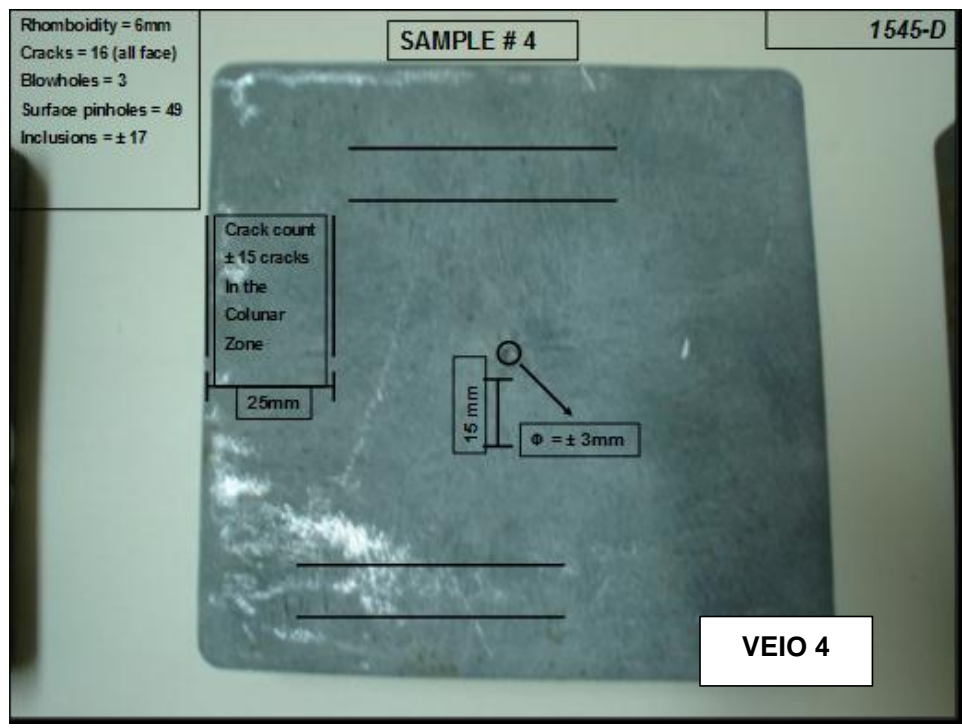

Figura 7. Macrografia amostra 4.

* Contribuição técnica ao 450 Seminário de Aciaria - Internacional, 25 a 28 de maio de 2014 Porto Alegre, RS, Brasil. 

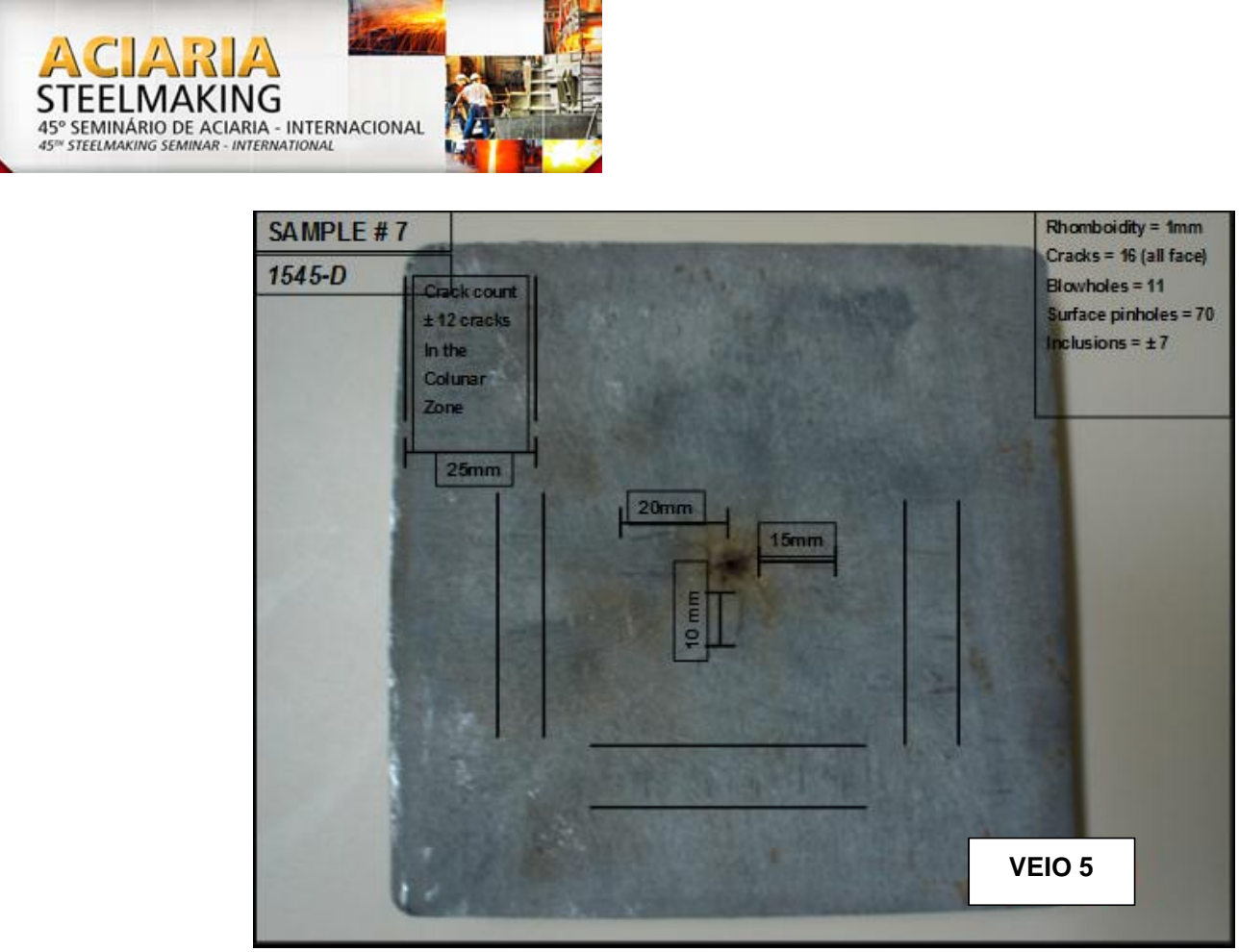

Figura 8. Marografia amostra 7.

Observa-se que o número de trincas subsuperficiais encontradas nas faces das amostras, Figura 9, não sofreu grande variação por veio, comprovando que não se trata de um problema localizado.

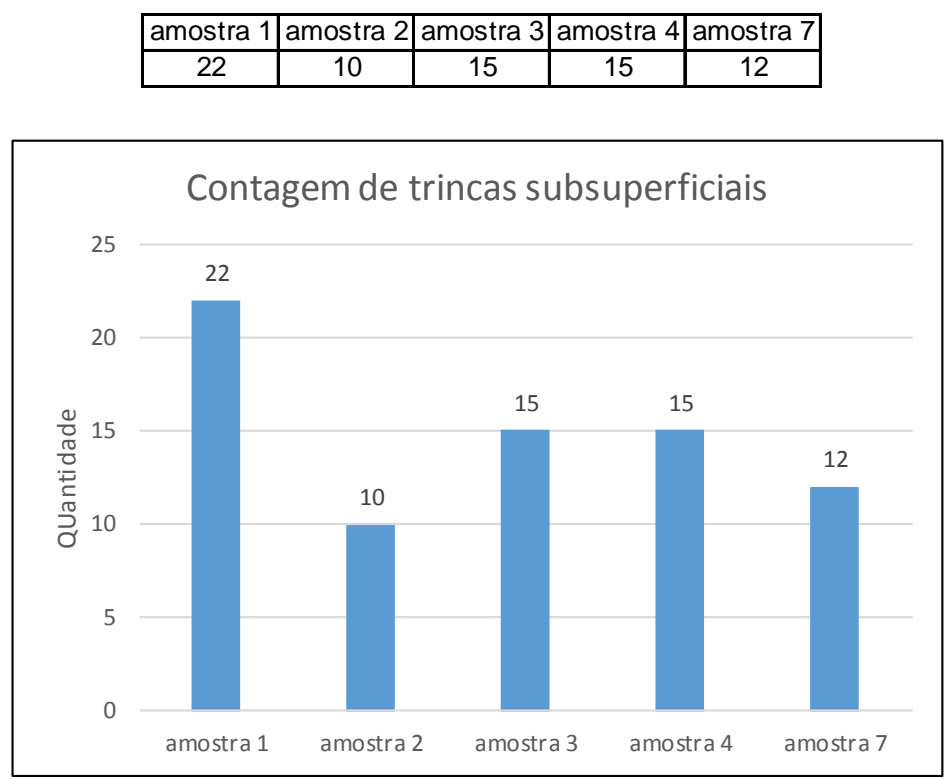

Figura 9. Gráfico de contagem de trincas subsuperficiais.

A partir da curva de refrigeração secundária da máquina de lingotamento atual, como referido anteriormente, observa-se a existência de uma grande queda de intensidade de refrigeração entre a zona 2 e 3 . Este fato intensifica a susceptibilidade ao defeito quando se tem uma velocidade de lingotamento é maior em um determinado veio. Devido a esta razão o veio 1, amostra 1, apresentou contagem de trincas subsuperficiais superior à média dos demais veios.

De posse destes resultados, pode-se deduzir através da fórmula de espessura da camada solidificada do tarugo, que as trincas subsuperficiais encontradas via análise macrográfica, ocorreram especificamente entre as zonas 2 e $3 a$ do sistema de

* Contribuição técnica ao $45^{\circ}$ Seminário de Aciaria - Internacional, 25 a 28 de maio de 2014, 
refrigeração secundária, conforme já indicava curva de intensidade de refrigeração da máquina. Tais cálculos encontram-se detalhados a seguir.

$\mathrm{S}=$ Espessura da pele $(\mathrm{mm})$

$$
\mathrm{S}=\mathrm{K} \times \mathrm{t}^{1 / 2}
$$

$\mathrm{t}=$ Tempo de lingotamento para crescimento da pele solidificada (min)

$\mathrm{K}=$ Constante de Solidificação, $24 \sim 26$ ( $\mathrm{mm} \mathrm{min-1/2)}$

Profundidade das trincas subsperficiais $=25 \mathrm{~mm}$, conforme resultado de

macrografias.

Aplicando a fórmula:

- $25=25 \times \mathrm{t}^{1 / 2}$

- $t=(25 / 25)^{2}$, onde $t=1,00$ minuto

Velocidade de Lingotamento $=2,8 \mathrm{~m} / \mathrm{min}$

Distância desde o menisco na qual ocorreram as trincas $=2,8 \times 1,00=2,80 \mathrm{~m}$, conforme indicado na Figura 10.

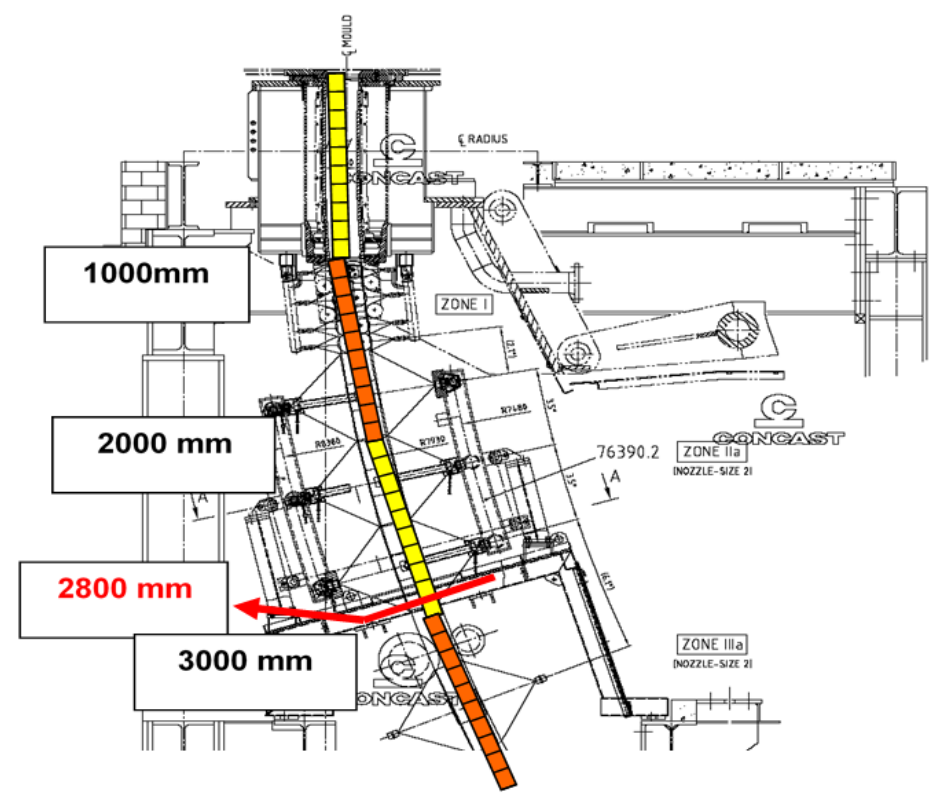

Figura 10. Localização do ponto onde ocorrem as trincas subsperficiais [5].

Vale ressaltar que as trincas foram observadas em todas as quatro direções de resfriamento confirmando claramente a existência de problemas de reaquecimento, ou seja, deficiência de refrigeração adequada entre as zonas 2 e 3.

\section{CONCLUSÃO}

A partir da curva de intensidade do novo sistema de refrigeração secundária do lingotamento contínuo e dos resultados das análises macrográficas, foi possível associar a origem de ocorrência dos defeitos de trinca subsuperficiais a uma deficiência do sistema de refrigeração da máquina ocasionado por um erro na elaboração do projeto do mesmo. Pôde-se precisar, também, a partir das análises realizadas o exato local, no qual a refrigeração secundária é falha. Os resultados encontrados apontam para a necessidade de ajuste na curva de intensidade de refrigeração secundária, a fim de se para a queda abrupta de vazão de água entre as zonas 2 e 3a. Existe, ainda, a recomendação de reposicionar os bicos nessa região, com objetivo de minimizar a ocorrência de trincas subsuperficiais causadas por sobreaquecimento.

* Contribuição técnica ao $45^{\circ}$ Seminário de Aciaria - Internacional, 25 a 28 de maio de 2014, Porto Alegre, RS, Brasil. 


\section{REFERÊNCIAS}

1 Santos CA. Lingotamento Contínuo dos Aços [Curso básico de lingotamento contínuo]. 2013 [acesso em 30 nov. 2013]. Disponível em:< www.em.pucrs.br/nuclemat>.

2 Almeida CF. Qualidade interna dos tarugos [curso básico de lingotamento contínuo]. 2013 [acesso em 10 jan. 2014]. Disponível em: www.aciarianews.blogspot.com.

3 Ataíde EF. Qualidade Superficial dos tarugos. São Paulo: Votorantim Siderurgia; 2012.

4 Linhares HF. Defeitos em produtos do lingotamento contínuo. São Paulo: Votorantim Siderurgia; 2008.

5 Operanting \& Maintenance Manuals. Zurique: Concast SMS Group; October 2008.

6 Rushforth M. 05 Strand Continuous Billet Caster. Quality Optimization Report; feb. 2009.

* Contribuição técnica ao $45^{\circ}$ Seminário de Aciaria - Internacional, 25 a 28 de maio de 2014, 